\title{
NUMBERS OF RELATIVES OF SEVERELY SUBNORMAL CHILDREN*
}

\author{
BY \\ D. J. P. BARKER \\ Department of Social Medicine, University of Birmingham
}

Knox (1959) suggested that "the patterns revealed by counting the numbers of aunts, uncles, and possibly other non-descendant relatives, offer a new means of characterizing some congenital abnormalities, and that these patterns are probably caused by the genetic or environmental factors which contribute to the occurrence of these diseases". It is not known whether non-specific mental subnormality is associated with asymmetries in the numbers of liveborn non-descendant relatives.

Tips, Smith, and Meyer (1964) studied the family histories of thirty children with "idiopathic developmental retardation" and concluded that mothers and maternal aunts had a much increased rate of miscarriages and stillbirths. But this conclusion was based on small numbers and requires confirmation.

The present paper describes an investigation into the numbers of liveborn and stillborn sibs, uncles, aunts, and cousins of two groups of children with severe mental subnormality of unknown cause.

\section{Method}

Both groups comprised children who were born in Birmingham and were subsequently registered with the city's Public Health Department as unsuitable for education. The first group was composed of those who were born in the city during 1950-54 and whose parents were resident there at the time of the survey (September, 1964). All such children were identified and medical histories were compiled from hospital records and records of local authority medical officers. Children who had recognized conditions such as mongolism or microcephaly, or had had diseases such as meningitis to which subnormality may be attributed, were excluded.

* This work has been supported by grants from the Association for the Aid of Crippled Children and from the Medical Research Council.
Details of their medical histories were given in a previous publication (Barker, 1966). The 117 children who remained were regarded as having non-specific subnormality, and their parents were interviewed by Mental Welfare Officers from the city's Mental Health Service. Wherever possible each Mental Welfare Officer interviewed the parents of children for whose welfare he or she was responsible, or had been responsible before the child was admitted to a hospital for the subnormal.

The parents were asked to give the numbers of brothers, sisters, uncles, aunts, and male and female cousins of their subnormal children. Care was taken to include all relatives, live- and stillborn, and to exclude those related only through fostering, adoption, or other legal procedures. Questionnaires were completed for 112 of the 117 children, but in seventeen information was lacking about either paternal or maternal relatives; 40 interviews were conducted with both the mother and father, 63 with the mother alone, five with the father alone, and four with other relatives.

The results from these data required confirmation and a further survey was carried out. The second group of children comprised those who were born in Birmingham during 1955-59, and whose parents were resident there at the time of the survey (September, 1965). Medical histories were compiled from the same sources as before and 64 children with nonspecific subnormality were identified. Again Mental Welfare Officers interviewed the parents but, in order to make the questionnaire more brief, information about stillbirths was not requested. Questionnaires were completed for 59 of the children, but in seven of them information was lacking about either paternal or maternal relatives; 21 interviews were conducted with both parents, 33 with the mother alone, three with the father alone, and two with other relatives. 
Results

Of the 171 subnormal children for whom data were obtained, 156 had I.Q.s below 50, and the other fifteen had I.Q.s between 50 and 65 . The numbers of liveborn males and females in the sibships of the children, and in those of their mothers and fathers, are shown in Table I. The results are subdivided according to the sex of the subnormal propositi.

Knox (1959) demonstrated that the male:female ratio in each type of sibship should be normal after exclusion of individuals through whom the sibships were ascertained, namely the propositi and their parents. The results of the first survey do not show this expected symmetry, as there are fewer females than males in the paternal sibships of male propositi. The second survey was carried out in order to confirm this finding and the results show the same imbalance, although the numbers are smaller. When the two sets of observations are combined there is little deviation from symmetry except in the paternal sibships of male propositi. In addition the mean number of each class of relative except paternal aunts is greater for subnormal boys than for subnormal girls. Among cousins of subnormal children there is no marked asymmetry that occurs in the results of both surveys (Table II).

Table III shows the stillbirth rates per cent.

TABLE III

STILLBIRTH RATE AMONG CHILDREN OF RELATIVES OF 112 SEVERELY SUBNORMAL PROPOSITI

\begin{tabular}{|c|c|c|}
\hline \multirow{2}{*}{ Relative } & \multicolumn{2}{|c|}{ Stillbirth Rate per 100 Total Births } \\
\hline & Male Propositi & Female Propositi \\
\hline Mother & $\begin{array}{l}3 \cdot 2 \\
\text { (7) }\end{array}$ & $\begin{array}{l}3 \cdot 8 \\
(4)\end{array}$ \\
\hline Mother's Mother & $\begin{array}{l}2 \cdot 6 \\
\text { (9) }\end{array}$ & $\begin{array}{l}0.0 \\
(0)\end{array}$ \\
\hline Mother's Brother & $\begin{array}{l}0.9 \\
\text { (2) }\end{array}$ & $\begin{array}{l}0.8 \\
\text { (1) }\end{array}$ \\
\hline Mother's Sister & $\begin{array}{l}3 \cdot 5 \\
(10)\end{array}$ & $\begin{array}{l}1.5 \\
\text { (3) }\end{array}$ \\
\hline Father's Mother & $\begin{array}{l}1 \cdot 3 \\
\text { (3) }\end{array}$ & $\begin{array}{l}8 \cdot 0 \\
(13)\end{array}$ \\
\hline Father's Brother & $\begin{array}{l}3 \cdot 3 \\
\text { (7) }\end{array}$ & $\begin{array}{l}4 \cdot 0 \\
(5)\end{array}$ \\
\hline Father's Sister & $\begin{array}{l}5 \cdot 3 \\
(9)\end{array}$ & $\begin{array}{l}5 \cdot 7 \\
\text { (7) }\end{array}$ \\
\hline
\end{tabular}

Numbers of stillbirths given in brackets.

NUMBERS OF SIBS AND PARENTAL SIBS OF 171 SEVERELY SUBNORMAL CHILDREN

\begin{tabular}{|c|c|c|c|c|c|c|c|}
\hline \multirow{2}{*}{$\begin{array}{c}\text { Sex of } \\
\text { Propositi }\end{array}$} & \multirow{2}{*}{ Survey } & \multicolumn{2}{|c|}{ Sibs } & \multicolumn{2}{|c|}{ Mother's Sibs } & \multicolumn{2}{|c|}{ Father's Sibs } \\
\hline & & Male & Female & Male & Female & Male & Female \\
\hline \multirow{3}{*}{ Male } & $\begin{array}{l}\text { First } \\
\text { Second }\end{array}$ & $\begin{array}{r}107 \\
64\end{array}$ & $\begin{array}{r}107 \\
49\end{array}$ & $\begin{array}{r}161 \\
71\end{array}$ & $\begin{array}{r}154 \\
94\end{array}$ & $\begin{array}{r}154 \\
80\end{array}$ & $\begin{array}{r}123 \\
66\end{array}$ \\
\hline & Total & 171 & 156 & 232 & 248 & 234 & 189 \\
\hline & Mean* & $1 \cdot 6$ & $1 \cdot 5$ & $2 \cdot 2$ & $2 \cdot 4$ & $2 \cdot 3$ & $1 \cdot 8$ \\
\hline \multirow{3}{*}{ Female } & $\begin{array}{c}\text { First } \\
\text { Second }\end{array}$ & $\begin{array}{l}43 \\
32\end{array}$ & $\begin{array}{l}59 \\
23\end{array}$ & $\begin{array}{l}90 \\
37\end{array}$ & $\begin{array}{l}90 \\
28\end{array}$ & $\begin{array}{l}71 \\
43\end{array}$ & $\begin{array}{l}67 \\
51\end{array}$ \\
\hline & Total & 75 & 82 & 127 & 118 & 114 & 118 \\
\hline & Mean* & $1 \cdot 2$ & $1 \cdot 3$ & $2 \cdot 0$ & $1 \cdot 9$ & $1 \cdot 8$ & 1.9 \\
\hline
\end{tabular}

* The mean is calculated as the number of sibs divided by the number of propositi for whom details of the class of sib are known.

TABLE II

NUMBERS OF COUSINS OF 171 SEVERELY SUBNORMAL CHILDREN

\begin{tabular}{|c|c|c|c|c|c|c|c|c|c|}
\hline \multirow{3}{*}{$\begin{array}{c}\text { Sex of } \\
\text { Propositi }\end{array}$} & \multirow{3}{*}{ Survey } & \multicolumn{8}{|c|}{ Number of Cousins by } \\
\hline & & \multicolumn{2}{|c|}{ Maternal Uncles } & \multicolumn{2}{|c|}{ Maternal Aunts } & \multicolumn{2}{|c|}{ Paternal Uncles } & \multicolumn{2}{|c|}{ Paternal Aunts } \\
\hline & & Male & Female & Male & Female & Male & Female & Male & Female \\
\hline \multirow{2}{*}{ Male } & $\begin{array}{l}\text { First } \\
\text { Second }\end{array}$ & $\begin{array}{r}114 \\
43\end{array}$ & $\begin{array}{l}94 \\
40\end{array}$ & $\begin{array}{r}139 \\
85\end{array}$ & $\begin{array}{r}131 \\
81\end{array}$ & $\begin{array}{r}109 \\
49\end{array}$ & $\begin{array}{l}89 \\
58\end{array}$ & $\begin{array}{l}67 \\
65\end{array}$ & $\begin{array}{l}95 \\
55\end{array}$ \\
\hline & Total & 157 & 134 & 224 & 212 & 158 & 147 & 132 & 150 \\
\hline \multirow{2}{*}{ Female } & $\begin{array}{l}\text { First } \\
\text { Second }\end{array}$ & $\begin{array}{l}59 \\
40\end{array}$ & $\begin{array}{l}58 \\
22\end{array}$ & $\begin{array}{l}95 \\
16\end{array}$ & $\begin{array}{l}92 \\
27\end{array}$ & $\begin{array}{l}67 \\
31\end{array}$ & $\begin{array}{l}49 \\
36\end{array}$ & $\begin{array}{l}61 \\
37\end{array}$ & $\begin{array}{l}52 \\
42\end{array}$ \\
\hline & Total & 99 & 80 & 111 & 119 & 98 & 85 & 98 & 94 \\
\hline
\end{tabular}


among children of relatives of the subnormal propositi in the first survey. These results may be compared with the stillbirth rates per 100 total births in England and Wales, which fell from 4.0 in 1928 to 1.7 in 1963. Although the small numbers make interpretation difficult, the rates are higher among fathers' relatives than among mothers', and for both male and female propositi they are especially high among the children of fathers' sisters. For female propositi there is a rate of 8.0 per cent. among the children of fathers' mothers, but this finding can be attributed to one family in which the mother had eleven stillbirths.

\section{Discussion}

A count of numbers of non-descendant relatives of two groups of severely subnormal children has revealed two asymmetries. There are more males than females in the paternal sibships of subnormal boys; and the mean number of sibs and of each class of uncle and aunt except paternal aunts is greater for subnormal boys than for subnormal girls. Similar findings have been recorded among relatives of children with congenital heart disease (Knox, 1959). The low mean number of paternal aunts of subnormal boys suggests that the high male:female ratio in their paternal sibships results from a reduced number of females rather than an increased number of males.

The cause of both asymmetries is obscure. Their nature seems to exclude any simple artefact as an explanation, and neither environmental hypotheses nor hypotheses based on autosomal, sex-linked, or partially sex-linked inheritance seem to provide a solution. On the basis of a null hypothesis of a male: female ratio of unity, the $\chi^{2}$ value of the findings in paternal sibships may be calculated as $4.79(P=0.03)$; and on the basis of a null hypothesis of an equal mean number of sibs, uncles, and aunts of subnormal boys and subnormal girls the $\chi^{2}$ value for the observed difference is $10.62(P=0.001)$. These small values of $\mathbf{P}$ indicate that such findings are unlikely to arise by chance, although they do not necessarily indicate that the findings are unlikely to have arisen by chance. Nevertheless the abnormality in the male:female ratio is marked and was recorded in both surveys, and the higher mean numbers of relatives of male propositi were also recorded in both surveys for all classes of relative, except paternal aunts.

Stillbirth rates among relatives of subnormal children were calculated from information given by the children's parents. The accuracy of statements about the stillbirths of grandmothers and parents' sibs could not be verified, but it was possible to compare the information obtained about the mothers' stillbirths with that on the obstetric records of the subnormal children. There were no previous stillbirths recorded in the obstetric histories which were not also recorded in this investigation. However, it is likely that information about the stillbirths of grandmothers would be less accurate, and it seems probable that their ascertainment was incomplete. Among the children of parents' sibs the rates are higher in the fathers' families than in the mothers', although the mothers, who were in many cases the sole informants, probably gave more complete information about their own families than about their husbands' families. It is concluded that these findings do not confirm those of Tips, Smith, and Meyers (1964), who found an increased rate of miscarriages and stillbirths among the children of mothers and maternal aunts. There is, on the contrary, some evidence of an increased stillbirth rate among fathers' relatives, especially among children of paternal aunts. This may be related to the mechanisms determining the apparent decrease in the numbers of paternal aunts of male propositi.

\section{Summary}

An analysis of the numbers of relatives of twa groups of children with severe mental subnormality: of unknown cause revealed two asymmetries in the numbers of sibs and parents' sibs. There were more males than females in the paternal sibships of subnormal boys; and the mean number of sibs and of each class of uncle and aunt except paternal aunts was greater for subnormal boys than for subnormal girls. There was also evidence of an increased stillbirth rate among the children of paternal aunts.

I am most grateful to the members of the Birmingham Public Health Department who helped in this investigation. Dr E. L. M. Millar, Medical Officer of Health, and Dr W. Nicol, Deputy Medical Officer of Health, made the department's records available. $\mathrm{Mr} \mathrm{A}$. Marrington, Chief Mental Welfare Officer, and his colleagues in the Mental Health Service collected the information about the subnormal children's families.

It is also a pleasure to thank Miss Gillian Davis for her help with the abstraction of data from medical records.

\section{REFERENCES}

Barker, D. J. P. (1966). Brit. J. prev. soc. Med., 20, 15. Knox, G. (1959). Ann. hum. Genet., 23, 251.

Tips, R. L., Smith, G., and Meyer, D. L. (1964). Pediatrics, 33, 100. 